\title{
A PRÁTICA DA GINÁSTICA GERAL PARA JOVENS E ADULTOS COM DEFICIÊNCIA INTELECTUAL: A EXPERIÊNCIA DO LAEFA/CEFD/UFES
}

\author{
Michelly de Menezes Garcia, Universidade Federal do Espírito Santo, Espírito Santo - \\ Brasil \\ Aron de Oliveira Pereira Vilete, Universidade Federal do Espírito Santo, Espírito Santo - \\ Brasil \\ Maria das Graças Carvalho Silva de Sá, Universidade Federal do Espírito Santo, Espírito \\ Santo - Brasil \\ José Francisco Chicon, Universidade Federal do Espírito Santo, Espírito Santo - Brasil
}

\section{RESUMO}

Este estudo se constitui enquanto uma Pesquisa Qualitativa com o intuito de descrever e analisar, a partir de uma experiência concreta de intervenção, o ensino da Ginástica Geral enquanto uma ferramenta potencializadora aos processos inclusivos de jovens e adultos com Deficiência Intelectual. O estudo toma como eixo central no âmbito teóricometodológico a Pesquisa Ação Colaborativa, pela possibilidade que esta perspectiva oferece aos envolvidos atuarem de maneira compartilhada na produção de saberes e fazeres pedagógicos. Os sujeitos participantes do estudo em tela são oriundos da APAE (Associação de Pais e Amigos dos Excepcionais) de Vitória/ES e da comunidade, totalizando um grupo de 30 alunos. Como instrumento de coleta de dados, utilizamos o registro das aulas em diários de campo, relatórios finais solicitados aos estagiários, fotografias, videogravações, além da realização de um grupo focal, aplicado no início de novembro, com os pais e/ou responsáveis pelos jovens e adultos. Os resultados apontam que o ensino da Ginástica Geral enquanto uma prática corporal pautada em ações inclusivas e democráticas, com foco na interação social, na relação comunicativa e na formação dos sujeitos, potencializa o processo de apropriação e (re) significação dos conhecimentos, auxiliando-os assim no estabelecimento de uma relação qualitativa com o meio sócio-cultural.

Palavras-Chave: Ginástica Geral; Deficiência intelectual; Inclusão.

\section{THE PRACTICE OF GENERAL GYMNASTICS FOR YOUNG PEOPLE AND ADULTS WITH INTELLECTUAL DISABILITY: THE EXPERIENCE OF LAEFA/CEFD/UFES}

\begin{abstract}
This study is constituted as a Qualitative Research in order to describe and analyze, from a concrete intervention, the teaching of general gymnastics as a tool for inclusive processes enhances of young people and adults with Intellectual Disabilities. The study takes as its central axis in the theoretical-methodological Collaborative Action Research for the possibility that this approach offers a way to act involved in the production of shared


knowledge and practice teaching. The participants in the study are from the screen APAE (Association of Parents and Friends of Exceptional Children) in Vitória/ES and the community, bringing the group of 30 students. As an instrument of data collection, use the registration classes in field diaries, final reports required for trainees, photographs, video recordings, besides conducting a focus group, applied in early November, with parents and /or guardians of young and adults. The results indicate that the teaching of General Gymnastics as a practice grounded in bodily actions inclusive and democratic, with a focus on social interaction, communicative relationship and training of individuals, enhances the process of appropriation and (re) signification of knowledge, helping them the way in establishing a qualitative relationship with the socio-cultural environment.

Key-Words: General gymnastics; Intellectual disabilities; Inclusion.

\section{LA PRÁTICA DE LA GIMNASIA GENERAL PARA JÓVENES Y ADULTOS COM DISCAPACIDAD INTELECTUAL: LA EXPERIENCIA DE LAEFA/CEFD/UFES}

\section{RESUMEN}

Este estudio se constituye como una investigación cualitativa con el fin de describir y analizar, a partir de una intervención concreta, la enseñanza de la gimnasia en general como una herramienta para la mejora de los procesos inclusivos de las personas jóvenes y adultas con discapacidad intelectual. El estudio toma como eje central teóricometodológico la investigación-acción de colaboración ara la posibilidad de que este enfoque ofrece una manera de actuar involucrado en la producción de conocimiento compartido y la práctica docente. Los participantes en el estudio son de la APAE (Asociación de Padres y Amigos de Niños Excepcionales) en Vitória/ES y la comunidad, con lo que el grupo de 30 estudiantes. Como instrumento de recolección de datos, utilizar las clases de registro en diarios de campo, los informes finales requeridos para los monitores, fotografías, grabaciones de vídeo, además de llevar a cabo un grupo de enfoque, aplicado a principios de noviembre, con los padres o tutores de los jóvenes y los adultos. Los resultados indican que la enseñanza de la Gimnasia General, como una práctica basada en acciones corporales inclusivas y democráticas, con un enfoque en la interacción social, la relación comunicativa y la formación de las personas, mejora el proceso de apropiación y (re) significación de los conocimientos, ayudándoles el camino para establecer una relación cualitativa con el entorno socio-cultural.

Palabras-Clave: Gimnasia general; Discapacidad intelectual; Inclusión. 


\section{INTRODUÇÃO}

Estudo concebido a partir de uma experiência concreta no processo de ensinoaprendizagem da Ginástica Geral para jovens e adultos com deficiência intelectual, participantes do projeto de extensão intitulado "Prática pedagógica em Educação Física para pessoas com deficiência intelectual", realizado no Laboratório de Educação Física Adaptada - LAEFA/CEFD/UFES - desde 2009, cujo objetivo centra-se na promoção de ações pedagógicas com caráter inclusivista focado na formação humana dos envolvidos, auxiliando-os na apropriação e (re) significação de conhecimentos que lhes possibilitem a autonomia e a independência necessária para interagir socialmente.

Ao direcionarmos nossas considerações para o âmbito da Educação Física brasileira, identificamos um momento profícuo para transformação, construção e (res) significação dos conhecimentos e práticas corporais, visto que esta área do conhecimento vem promovendo ações no sentido de sua universalização em todos os segmentos de nossa sociedade.

Ainda de acordo com a recomendação da Declaração de Salamanca, ${ }^{1}$ importante documento que ajudou a deflagrar o movimento de inclusão ${ }^{1}$ de pessoas com necessidades educacionais especiais na década de 90 em ambiente escolar comum, a educação de crianças com deficiência deve começar o mais cedo possível, com matriculas nas escolas de educação infantil, para que as crianças, sem os estigmas socioculturais, aprendam a conviver e respeitar as diferenças ao longo de seu processo de desenvolvimento.

Aprofundando um pouco mais o debate, ao refletirmos acerca dos processos de Educação/Educação Física Adaptada com base na Carta Internacional de Educação Física da $\mathrm{UNESCO}^{2}$ ao preconizar que a prática da Educação Física é um direito de todos, e seus programas devem dar prioridade principalmente aos grupos menos favorecidos da

\footnotetext{
${ }^{1}$ Tomamos este conceito a partir de Sassaki (2006), quando o autor nos aponta que a inclusão é um processo bilateral, no qual a sociedade deve adaptar-se para poder incluir, através de pequenas e grandes transformações (em ambientes físicos, equipamentos, aparelhos, mentalidade das pessoas, dentre outros), ao mesmo tempo em que as pessoas com necessidades especiais devem preparar-se para assumir seus papéis na sociedade.

Conexões: revista da Faculdade de Educação Física da UNICAMP, Campinas, v. 10, n. Especial, p. 39-55, dez. 2012.41 ISSN: 1983-9030
} 
sociedade, vislumbramos ainda muitos desafios a fim de se garantir o acesso e a permanência qualitativa dos alunos com deficiência nos ambientes educacionais. De forma que no âmbito das aulas de Educação Física este contexto não se diferencia.

Neste contexto, constituímos uma pesquisa que visa descrever e analisar a experiência do ensino da Ginástica Geral como uma ferramenta potencializadora aos processos inclusivos de jovens e adultos com Deficiência Intelectual.

A opção pela Ginástica Geral $(\mathrm{GG})^{2}$ alicerça-se na possibilidade de que esta prática corporal nos permite pensar o trabalho em grupo, a liberdade de expressão, desenvolvimento da criatividade e a utilização de materiais convencionais e/ou alternativos, o que permite apropriar-se de elementos da ginástica circense. Sendo neste contexto de vivência em grupo, que valores e relações sociais são desenvolvidas, possibilitando a experimentação de novas e diferentes formas de convivência e sociabilidade.

Segundo Marcassa, ${ }^{3: 174}$ quando nos referimos às práticas corporais, estamos falando de uma forma de linguagem não verbal, mas repleta de sentidos e significados visto que nosso corpo carrega traços da cultura, onde os gestos e os movimentos tornam-se um "[...] campo fértil através do qual podemos conhecer e intervir sobre a realidade". Ainda de acordo com a autora, a possibilidade de saber/conhecer acerca das características do próprio corpo e dos movimentos que ali emergem, são fatores cruciais na construção da autonomia ${ }^{3}$ dos envolvidos.

A GG, então proporciona ao envolvidos um vasto leque de atividades físicas orientadas para o lazer, fundamentadas nas diferentes interpretações da Ginástica (Natural, Construída, Artística, Rítmica Desportiva, Aeróbica, etc.) integrando-as com outras formas de expressão corporal (Dança, Folclore, Jogos, Teatro, Mímica, etc.), de forma livre e

\footnotetext{
${ }^{2}$ Aqui compreendida como uma forma de linguagem corporal que possibilita o desenvolvimento do homem em todos os seus domínios: afetivo, corporal, social, cognitivo, etc, foi neste sentido que concebermos o quanto esta prática corporal propicia aos alunos se conhecerem em diferentes dimensões, ampliando assim, sua percepção acerca do próprio corpo (MARCASSA, 2004).

3 "Autonomia é a condição de domínio no ambiente físico e social, preservando ao máximo a privacidade e a dignidade da pessoa que exerce" (SASSAKI, 2006, p. 35).

Conexões: revista da Faculdade de Educação Física da UNICAMP, Campinas, v. 10, n. Especial, p. 39-55, dez. 2012. 42 ISSN: 1983-9030
} 
criativa, de acordo com as características do grupo social e contribuindo para o aumento da interação social entre os participantes, pois “[...] está aberta para a participação de todos, privilegiando os trabalhos em grupo", 4:54 apóia-se também na compreensão de que esta “[...] manifesta-se de modo articulado com as aspirações, projetos e relações existentes em nossa sociedade e, em qualquer circunstância, é uma forma de expressão não verbal de valores, idéias, concepções, saberes e práticas sociais", 3:173

Outra relevância significativa desta modalidade, refere-se ao caráter não competitivo que esta prática corporal assume, proporcionando a participação de todos dentro de suas possibilidades, limites, vivências, potencialidades e ideais. Pois esta é “[...] uma atividade regular dentro de um contexto de entusiasmo e de jogo, e a participação é, sobretudo, determinado pelo prazer de praticar". ${ }^{4: 39}$ Outras características como a simplicidade de movimentos, a participação irrestrita, a integração entre os indivíduos, o desenvolvimento da criatividade, entre outros, propiciam a disseminação dessa prática corporal e orientam esta para um trabalho inclusivo, democrático e criativo. ${ }^{5}$

Como eixo norteador da ação pedagógica, utilizamos a abordagem crítico emancipatória proposta por Kunz ${ }^{6: 139}$ por conceber nesta uma significativa ferramenta no sentido de "[...] preparar o aluno para uma competência do agir". De acordo com o autor, o professor tem a função de desafiar os seus alunos ao diálogo, esperando sempre uma resposta no âmbito individual ou coletivo. Cabe ressaltar, que nas aulas de Educação Física não apenas a linguagem verbal ganha destaque, mas todo o ser corporal, o 'se movimentar', são considerados uma forma de linguagem, utilizada pelo homem como uma maneira de comunica-se com o mundo. ${ }^{6}$

Para Sassaki, ${ }^{7}$ a formação de um sujeito com estilo de vida independente e autônomo é fundamental para o processo de inclusão, pois propiciará as pessoas com deficiência uma maior participação na sociedade de forma qualitativa.

\section{OBJETIVOS}

Descrever e analisar a experiência do ensino da Ginástica Geral como uma ferramenta potencializadora aos processos inclusivos de jovens e adultos com Deficiência Intelectual.

Para tanto nos pautamos nas seguintes ações:

Conexões: revista da Faculdade de Educação Física da UNICAMP, Campinas, v. 10, n. Especial, p. 39-55, dez. 2012. 43 ISSN: 1983-9030 
- Analisar os limites e as possibilidades dos alunos com deficiência intelectual na realização das atividades propostas para o ensino da Ginástica Geral;

- Interagir coletivamente em situações de aula, integrando os alunos com seus professores e as estagiárias;

- Narrar e discutir situações em que a ginástica geral se apresenta enquanto uma ferramenta potencializadora aos processos inclusivos de jovens e adultos com Deficiência Intelectual.

\section{METODOLOGIA}

O estudo em tela assumiu como eixo central de suas ações no âmbito teórico-metodológico a Pesquisa Ação Colaborativa, pela possibilidade que esta perspectiva oferece a todos os envolvidos (professores, estagiários, pesquisadores, alunos e familiares em geral) atuarem de maneira compartilhada na produção de saberes e fazeres pedagógicos. Para tanto toma a ação colaborativa entre pesquisadores, mediada pela relação dialógica, que se materializa nos círculos reflexivos, em que os sujeitos envolvidos no processo de intervenção pedagógica são coprodutores de conhecimentos. ${ }^{8} \mathrm{O}$ foco de interesse desta abordagem centra-se na produção de conhecimentos e nos processos de formação, reconciliando essas duas importantes dimensões da pesquisa em educação/Educação Física.

Os sujeitos participantes do projeto foram cerca de 30 jovens e adultos com deficiência intelectual, oriundos da APAE de Vitória/ES e da comunidade. As intervenções ocorreram às quintas feiras, sendo que um grupo de 15 alunos era atendido entre 14 e 14:50 horas e o segundo grupo também composto por 15 alunos eram atendidos entre 15:00 e 15:50 horas. Ao longo do segundo semestre de 2011, foram desenvolvidas 10 intervenções realizadas na sala de Ginástica Olímpica do CEFD/UFES. Para além das intervenções, tomamos como meta a elaboração de uma composição coreográfica apresentada ao final das atividades, onde demos visibilidade ao momento de protagonismo dos alunos.

No momento do atendimento, os estagiários assumiram as seguintes funções: dois dividem a coordenação das aulas e um realiza a videogravação das mesmas. Após cada aula, professores, estagiários e pesquisadores refletiam sobre os procedimentos didáticometodológicos utilizados naquele dia e planejavam as próximas intervenções tomando 
como eixo destas discussões as impressões, proposições e percepções captadas na aula anterior, refletindo, assim, sobre os problemas que surgem, organizando e reorganizando as atividades de aula de acordo com o interesse dos envolvidos. Esse procedimento assegura a sequência de uma aula para a outra, mantendo a coesão do desenvolvimento do conteúdo, o que representa, em nosso entender, um aspecto importante para o processo ensinoaprendizagem.

A coleta de dados se deu por meio do registro das aulas em diários de campo, relatórios finais solicitados aos estagiários, fotografias, videogravações, além da realização de um grupo focal, aplicado no início de novembro, com os responsáveis pelos jovens e adultos.

Os dados foram discutidos com base na Análise de Conteúdos ${ }^{9}$ pela possibilidade que esta técnica nos permite juntamente com o referencial teórico, compreender, efetivamente a contribuição da Ginástica Geral aos processos inclusivos de jovens e adultos com deficiência intelectual.

No que se refere á triangulação dos dados coletados, consideramos para registro e análise os momentos de aula com foco no compartilhamento entre o aluno com deficiência e seus colegas, o processo de organização, execução e avaliação das aulas, a importância da experiência em tela para os diferentes processos de desenvolvimento dos alunos com deficiência intelectual investigados.

\section{DELINEAMENTO TEÓRICO CONCEITUAL}

\section{A prática da Ginástica Geral para Jovens e adultos com deficiência intelectual}

Para além da valorização da autonomia e do desenvolvimento pessoal, social e afetivo condições importantes para o processo de inclusão - a prática da GG também possibilita a interação social entre os participantes, pois é uma prática corporal pautada na valorização de atividades coletivas.

Nesse sentido, Kunz ${ }^{6}$ nos evidencia o fato de que a interação social ocorre em todo processo coletivo de ensinar e aprender, todavia cabe ao professor tematiza-lá de forma crítica, para que, efetivamente, esta atenda aos objetivos educacionais que valorizam o trabalho responsável de forma coletiva, cooperativa e participativa. Portanto a valorização Conexões: revista da Faculdade de Educação Física da UNICAMP, Campinas, v. 10, n. Especial, p. 39-55, dez. 2012. 45 ISSN: 1983-9030 
da interação no processo educativo assume um papel fundamental na perspectiva da inclusão, pois é por meio desta modalidade que as relações sociais se constituem, sendo essencial para se estabelecer uma relação qualitativa com os meios sócio-cultural e sócioeducacional.

Além da interação, $\mathrm{Kunz}^{6}$ destaca mais duas modalidades de ensino fundamentais, estas são: trabalho e a linguagem. $\mathrm{O}$ autor postula a importância do uso da linguagem nas situações de ensino, quando destaca que por meio desta modalidade os envolvidos no processo de ensino-aprendizagem podem participar ativamente "[...] em todas instâncias de decisão, na formulação de interesses e preferências, e agir de acordo com as situações e as condições do grupo em que está inserido". 6:123

Sendo assim, destacamos a necessidade de se estabelecer uma relação dialógica com os alunos, pois, por meio desta modalidade, expressões e valores são colocados, de modo que, os envolvidos se sintam sujeitos pertencentes e ativos do processo educacional. Além de contribuir efetivamente para a apropriação dos conhecimentos que estão sendo construídos e/ou (re) significados.

O trabalho por sua vez, é colocado por Kunz ${ }^{6: 139}$ como a possibilidades do aluno "transcender seus limites", pois nesta modalidade o aluno através dos conhecimentos adquiridos na relação com o mundo, tem a possibilidade de desenvolver e qualificar suas habilidades e consequentemente "[...] o seu espaço de atuação e as suas possibilidades de autodeterminação e codeterminação nas atividades de ensino". Para tanto, é incumbência de professor criar situações-problemas, onde os seus alunos sejam desafiados, a fim de, conhecer suas possibilidades e desenvolver suas potencialidades, sem necessariamente fazer uso de uma técnica especifica.

Nesse aspecto, corroboramos com Kunz, ${ }^{6}$ quando postula sobre a importância da ação pedagógica pautada nessas três modalidades de ensino, principalmente quando concebemos o aluno enquanto sujeito deste processo, portanto, este deve capacitá-lo a fim de valorizar a sua participação na vida social, cultural e esportiva, potencializando, assim, a possibilidade de conhecer, reconhecer e problematizar sentidos e significados nesta vida, através de uma reflexão crítica.

Conexões: revista da Faculdade de Educação Física da UNICAMP, Campinas, v. 10, n. Especial, p. 39-55, dez. 2012.46 ISSN: 1983-9030 
Por conceber o conceito crítico como sendo a capacidade do aluno de questionar e analisar as condições e a complexidade da vida social de maneira fundamentada e o conceito emancipatório como sendo o processo de libertação do mesmo de condições limitadoras de suas capacidades racionais, ${ }^{10}$ entendemos que a perspectiva crítico-emancipatória favorece o processo de inclusão dos jovens e adultos com deficiência intelectual, no sentido de potencializar o constante diálogo entre professor-aluno, contribuindo assim, para apropriação e (re) significação dos conhecimentos necessários para a reflexão crítica das ações e para o desenvolvimento da autonomia.

Nesse sentido, apresentamos para discussão as três categorias de análise, a saber:

1) $\mathrm{O}$ Ambiente enquanto agente potencializador;

2) Interação Social e Relação Dialógica;

3) Mediação pedagógica e mudanças comportamentais e atitudinais.

\section{RESULTADOS E DISCUSSÕES}

\section{O Ambiente enquanto agente potencializador}

Ao retomarmos o conceito de GG enquanto uma prática corporal que valoriza a participação de todos dentro dos seus limites, ideais, possibilidades e potencialidades, Ayoub $^{4: 54}$ nos apresenta que "[...] a ginástica geral esta aberta para a participação de todos, privilegiando os trabalhos em grupo". Nesta perspectiva, vislumbramos que a GG por si só, já é uma prática que facilita a interação entre os indivíduos, por ser uma prática caracterizada pelo prazer em praticar, pela liberdade de expressão, diversão, dentre outros fatores, sabemos, porém, que ela não pode ser algo isolado.

Partindo dessa premissa, optamos por potencializar o 'ambiente', de modo que este se constituísse enquanto em elemento contributivo para as relações sociais que ali se produziam. Dentre os elementos elencados enquanto potencializadores destacaremos: a música e a utilização dos materiais convencionais e/ou alternativos.

A opção pela música no ambiente adveio, pois, anteriormente, delimitamos como tema das nossas intervenções a ginástica com elementos circenses, deste modo, elencamos algumas músicas que continha a temática circo para perpassar as intervenções, com o intuito de Conexões: revista da Faculdade de Educação Física da UNICAMP, Campinas, v. 10, n. Especial, p. 39-55, dez. 2012. 47 ISSN: 1983-9030 
focalizar qual era o tema do projeto. Ocorreu que música se constituiu enquanto um elemento potencializador do processo de socialização dos sujeitos. Como é possível observar no registro seguinte:

Durante essa intervenção observei que, sempre que a música se faz presente há uma grande mobilização por parte do grupo em participar das atividades. $O$ aluno T. que de início fica bem quieto acabou no decorrer da atividade se soltando e foi possível observar ele por diversas vezes sorrindo e interagindo com alguns monitores (Diário de campo, n², 01/09/2011).

Nota-se, que a música se constituiu enquanto um estímulo para que o grupo participasse efetivamente das atividades, favorecendo deste modo as trocas e inter-relações, assim como em relação ao aluno T, que de início estava quieto e depois foi 'se soltando', de modo que ele participasse da aula sorrindo e interagindo com os demais monitores.

Outro elemento, considerado contributivo para as trocas entre os alunos-alunos e, estes com seus monitores, foi à utilização de materiais convencionais e alternativos como objetos que perpassavam as intervenções. Ressaltamos que para além de favorecedores das relações, estes materiais também se constituíram enquanto fovente das potencialidades/possibilidades dos alunos envolvidos. Para tanto, destacaremos o aluno J. Este possui hemiplegia, que se caracteriza pela paralisia completa de um hemisfério (lados) do corpo. Entretanto, para além da sua limitação física, este mostrou extrema facilidade em manejar arcos e bolas (elementos constituintes da ginástica rítmica), como é possível observar na narrativa que segue:

Interessante nessa apresentação foram às reações das pessoas em relação ao J, que apesar de possuir uma "limitação física" não deixava a bola sair do seu controle, os pais que acompanhavam a apresentação ficavam impressionados com a habilidade dele em manipular a bola, dando sempre um jeito para que ela não caísse no chão. Ficaram até surpresos quando um dos monitores deixou a bola cair no chão e ele que possui aquela "limitação" não deixava de jeito nenhum a bola sair do controle (Diário de campo, $\left.n^{\circ} 12,17 / 11 / 2011\right)$.

Interessante ressaltar nessa narrativa, duas situações: primeiro, destacamos a potencialidade/possibilidade do aluno $\mathrm{J}$, que apesar da limitação física decorrente da hemiplegia, conseguiu por meio da utilização do instrumento bola, potencializar suas possibilidades, momento esse valorizado ainda mais em decorrência da apresentação 
coreográfica que estava acontecendo no dia, nesse sentido destacamos que esse movimento evidenciou ainda mais o processo desenvolvido, além de se constituir enquanto um elemento estimulante para os praticantes ali envolvidos. ${ }^{5}$ Nessa perspectiva, destacamos que "[...] o ensino deve fomentar, para tanto, a capacitação dos alunos para um agir solidário, nos princípios de codeterminação e autodeterminação". 6:37

O segundo ponto que evidenciamos, é em relação ao olhar dos pais e dos ali presentes mediante a essa situação. Nota-se, a surpresa de muitos ali presentes com a 'habilidade' do aluno $\mathrm{J}$ em relação ao manuseio do aparelho, nesse sentido evidenciamos o quanto essa situação foi fundamental para que muitos presentes conseguissem visualizar além das limitações deste e dos demais alunos e enxergasse as potencialidades dos mesmos, nessa perspectiva trazemos a fala de Sacks apud Bianchetti e Correia ${ }^{11: 151}$ quando ele nos aponta que "[...] o olhar é uma maneira de se posicionar no mundo e diante dele. O olhar é uma linguagem que se constrói e se realiza no contato com os outros, nas inter-relações".

\section{Interação Social e Relação Dialógica}

Esta categoria visa discorrer sobre as contribuições da interação social e da relação dialógica estabelecida entre os envolvidos, no processo de inclusão dos jovens e adultos com deficiência intelectual. Cabe ressaltar, que a relação comunicativa ${ }^{4}$, não está pautada apenas no que se referem à linguagem verbal, mas nas diversas manifestações signicas que esta forma de expressão pode se constituir/materializar.

Esse processo comunicativo estabelecido entre os envolvidos foi fundamental para que eles se sentissem enquanto sujeitos daquela ação, pois por meio dessa troca era possível observar e analisar as demandas solicitadas pelo grupo, que posteriormente eram utilizadas como eixo norteador para desenvolvermos as próximas ações. Outro fator é que essa relação propiciou a aproximação dos alunos/sujeitos, e os mesmos com os professores, esse movimento auxiliou de maneira significativa no processo de interação de todos os envolvidos. $\mathrm{Kunz}^{6}$ destaca que estas relações entre alunos-alunos e alunos-professores não

\footnotetext{
${ }^{4}$ Por Ação Comunicativa denominamos aquelas ações que têm a sua finalidade nos próprios sujeitos participantes da mesma; que não provém de um domínio natural dado (também não é uma 'produção'), mas que pretende alcançar a compreensão sobre o Sentido e os Objetivos das Ações (MOLLENHAUER, apud KUNZ, 1991, p.138).

Conexões: revista da Faculdade de Educação Física da UNICAMP, Campinas, v. 10, n. Especial, p. 39-55, dez. 2012. 49 ISSN: 1983-9030
} 
podem ocorrem sem uma relação dialógica, pois a linguagem é o agente mediador desta relação, nesse sentido o conhecimento técnico, cultural e social só poderá ser compreendido por meio da interação e da linguagem. O autor postula que são as “[...] interações que contribuem para o desenvolvimento da competência social do aluno, competência necessária não apenas para o sentido de cooperação e participação ativa e crítica no mundo $[\ldots]^{\prime,}$. 10:27

Corroboramos ainda com Vygotsky apud Oliveira, ${ }^{12: 64}$ quando nos aponta que “[...] qualquer modalidade de interação social, quando integrada num contexto realmente voltado para a promoção do aprendizado e do desenvolvimento, poderia ser utilizada, portanto, de forma produtiva na situação escolar".

Neste bojo, trazemos em tela duas falas coletas no grupo focal realizado com os responsáveis pelos jovens e adultos.

Eu vejo, que vocês vão lá pegam e trazem para junto, levam eles pra fazer as atividades como se não tivesse nenhuma deficiência, é o modo como vocês vão vendo, tratando, como se fosse uma pessoa normal. Então a gente acha que eles não percebem quando são olhados diferente, mas quando alguém trata eles diferente eles percebem, eles percebem sim (Responsável pelo aluno L, grupo focal, 10/11/2011).

[...] os projetos são maravilhosos, as pessoas são ótimas, são carinhosas, eles tem aquele 'tcham' pra lidar com as 'crianças', eles gostam de estarem aqui, eles vem pra cá porque gostam, então todas as outras coisas acontecem pelo fato de eles gostarem de estar aqui (Responsável pela aluno J, grupo focal, 10/11/2011).

Conclui-se, então, que a relação comunicativa estabelecida entre os envolvidos foi fundamental para o processo de socialização ${ }^{5}$ dos sujeitos, de modo que esta troca contribui efetivamente para o processo de construção da autonomia destes, qualificando, as relações socioculturais e sócio-educacionais ali produzidas. Como nos apresenta Kunz, ${ }^{13: 138}$ toda ação pedagógica deve ser compreendida “[...] como uma ação socialmente regulamentada onde, no entanto, os participantes nas interações, de ambos os lados, devam

\footnotetext{
5 Compreendido como "[...] o espaço privilegiado da transmissão social dos sistemas de valores, dos modos de vida, das crenças e das representações, dos papéis sociais e dos modelos de comportamento”.(BELLONI, M. L. Infância, mídias e educação: revisitando o conceito de socialização. Perspectiva, Florianópolis, v. 25, n. 1, 41-56, jan./jun. 2007).
}

Conexões: revista da Faculdade de Educação Física da UNICAMP, Campinas, v. 10, n. Especial, p. 39-55, dez. 2012.50 ISSN: 1983-9030 
ser considerados como sujeitos dessa ação". Nessa perspectiva também ganha destaque as diferentes e diversas formas de linguagem estabelecidas nas relações sociais, principalmente a linguagem do "se movimentar", por meio das quais muitos podiam expressar-se e comunicar-se através dos gestos e movimentos que ali emergiam, ressaltando, que o nosso corpo carrega consigo traços da nossa cultura.

\section{Mediação ${ }^{6}$ pedagógica e mudanças comportamentais e atitudinais}

Nesta categoria de análise, centraremos nossas discussões a respeito das contribuições da mediação pedagógica na prática da GG para as mudanças comportamentais e atitudinais dos alunos com deficiência intelectual. Para tanto, fizemos um recorte e optamos pela escolha dos alunos N e D. Estes possuem síndrome de Down, com um comprometimento na fala, por isso não possui comunicação verbal. A escolha destes alunos se deu, pois, no início do projeto ambos pouco se relacionavam com o restante do grupo e com os demais professores, o aluno $\mathrm{N}$ principalmente, passava grande parte das intervenções sentado, e raramente interagia com materiais/objetos e/ou aparelhos presentes na sala de ginástica artística, D por sua vez, passava grande parte do tempo de cabeça inclinada para baixo. Como é possível observar nas seguintes narrativas:

O N ficava muito sentado, não dava as mãos para ninguém e raramente olhava para mim (Relatório final solicitado aos estagiários - professora K).

O D levantava com mais frequência, mas nunca olhava para mim, sempre de cabeça baixa e não respondia (de nenhuma forma) as nossas falas. Ele também tinha dificuldade em me dar às mãos, como também na hora de apresentar os materiais da aula (Relatório final solicitado aos estagiários - professora $L$ ).

Depois de observadas as limitações dos alunos $\mathrm{N}$ e $\mathrm{D}$, procuramos durante os planejamentos $^{7}$, pensar estratégias para que durante as intervenções os alunos se aproximassem/interagissem com os demais colegas do grupo, de modo que, aos poucos também participassem das atividades que estavam sendo propostas. Definimos então, que durante as intervenções $\mathrm{N}$ e D sempre estariam acompanhados por um monitor/professor, de forma que este tinha como função mediar e potencializar as relações de ambos com os

\footnotetext{
${ }^{6}$ Concebemos este conceito a partir de pressupostos sócio históricos como processo pelo qual um elemento intermediário (mediador), visa potencializar/favorecer as relações entre os sujeitos envolvidos no processo de ensino-aprendizagem.

${ }^{7}$ Estabelecidos como “[...] momento de dialogar sobre a experiência que está sendo vivida no processo de desenvolvimento do projeto" (AYOUB, 2004, p.28).

Conexões: revista da Faculdade de Educação Física da UNICAMP, Campinas, v. 10, n. Especial, p. 39-55, dez. 2012.51 ISSN: 1983-9030
} 
demais colegas, professores e materiais/objetos e/ou aparelhos. Nesse sentido destacamos que “[...] o professor é responsável por organizar atividades educacionais que possibilitem ao indivíduo criar e, consequentemente, internalizar o conhecimento social". 14:220

Tanto $D$ quanto o $N$ precisavam de um incentivo para se levantar e fazer um determinado movimento. Comecei a ficar bem perto, sentada na frente deles e a 'brincar' com algum material para que eles olhassem e tivessem interesse (Relatório final solicitado aos estagiários - professora K).

Nota-se na narrativa de uma das monitoras, que o meio utilizado para conseguir a atenção dos alunos se deu por meio da utilização de materiais que podem ser convencionais e/ou alternativos, já que a GG possibilita essa liberdade na escolha dos objetos a serem trabalhados, nesse sentido destacamos a importância de se fazer uso dos materiais durante as aulas de GG, pois com nos apresenta Nunomura e Tsukamoto, ${ }^{5: 40}$

A criatividade é estimulada quando os praticantes "descobrem" diferentes formas de movimentar um determinado material, de combiná-lo aos movimentos ginásticos ou às demais formas de movimentar o corpo (individualmente ou em grupo) ou ao que se deseja expressar, ou seja, o limite é a criatividade das pessoas envolvidas.

Com o decorrer das intervenções algumas mudanças atitudinais puderam ser observadas, dentre as quais destacamos a relação estabelecida entre $\mathrm{D}$ e $\mathrm{N}$ com a monitora que os acompanhavam durante algumas intervenções, como podemos observar na narrativa da monitora:

$O N$ até me abraçou, demonstrando carinho e confiança. Já o D começou a sorrir e olhar para mim com a cabeça mais levantada (Relatório final solicitado aos estagiários - professora $K$ ).

Mudanças de comportamento também foram observadas, como a participação mais presente e ativa nas aulas, destacada nas seguintes falas:

O N mostrou-se mais ativo nas aulas usando o material, jogando bola, olhando para o espelho, rindo, abraçando e prestando mais atenção nas minhas falas (Relatório final solicitado aos estagiários - professora K).

Novamente as monitoras optaram por explorar o objeto com o D, elas colocaram dentro do casaco dele e esperavam para ver a sua reação. De início mostrou-se um pouco assustado, mas habituando-se a presença do material chegou a pegá-lo e a retirá-lo do casaco. Novamente o objeto foi entregue ao D, ele então o segurou e o colocou dentro do casaco, para surpresa das monitoras. Entregaram um novo objeto e ele novamente pegou e colocou no casaco. (Diário de campo, $\left.n^{\circ} 8,20 / 10 / 2011\right)$.

Conexões: revista da Faculdade de Educação Física da UNICAMP, Campinas, v. 10, n. Especial, p. 39-55, dez. 2012. 52 ISSN: 1983-9030 
Destacamos neste movimento o processo de mediação, estabelecido entre as professoras/monitoras com os alunos ( $\mathrm{D}$ e $\mathrm{N}$ ), enquanto fundamental para $\mathrm{o}$ desenvolvimento dos alunos, na medida em que este favoreceu a participação mais efetiva dos alunos nas intervenções, o que contribuiu para fomentar as relações sociais. Em nosso entender, é por meio destas ações que o sujeito aprende e se desenvolve culturalmente, atribuindo, assim, sentidos e significados as suas ações, e consequentemente desenvolvendo sua competência/autonomia, social, pessoal e cultural. Nesse sentido corroboramos com Vygotsky, ${ }^{15}$ quando o postula que o professor precisa assumir o papel de provocador de avanços em seus alunos, visto que este processo não ocorre espontaneamente.

\section{CONSIDERAÇÕES FINAIS}

Os dados deste estudo evidenciaram a significativa contribuição da GG, enquanto uma prática corporal focada na interação e formação humana dos envolvidos, pautada principalmente em ações comunicativas e dialógicas entre alunos-alunos e alunosprofessores, auxiliando os mesmos no processo de construção/desenvolvimento da autonomia, ferramenta fundamental para se constituir uma relação qualitativa com os contextos sociocultural e sócio educacional.

Destarte, se faz necessário evidenciar a efetiva contribuição dos professor/monitores nesse movimento, enquanto mediadores, através da relação dialógica estabelecida com os alunos no processo de ensino-aprendizagem, pois como demonstra Kunz, ${ }^{6: 145}$ é por meio da comunicação que se tem início o processo de "[...] auto-conhecimento e conhecimento do outro nas relações sociais", movimento necessário e fundamental para o processo de socialização.

Também evidenciamos a contribuição dessa experiência no processo de formação dos monitores envolvidos, visto que como apresenta Nóvoa, ${ }^{16: 28 ~ “[. . .] ~ a ~ f o r m a c ̧ a ̃ o ~ p a s s a ~ p e l a ~}$ experimentação, pela inovação, pelo ensaio de novos modos de trabalho pedagógico. E por uma reflexão crítica sobre a sua utilização". 


\section{REFERÊNCIAS}

${ }^{1}$ DECLARAÇÃO DE SALAMANCA. Conferência Mundial sobre Necessidades

Educativas Especiais: acesso e qualidade. Salamanca, 1994.

${ }^{2}$ UNITED NATION EDUCATIONAL SCIENTIFIC AND CULTURAL ORGANIZATION (UNESCO). Carta Internacional da Educação Física e do Desporto. 1978.

${ }^{3}$ MARCASSA, L. Metodologia do ensino de ginástica: novos olhares, novas perspectivas. Pensar a Prática, Goiânia, v. 7, n. 2, p. 171-186, jul./dez. 2004.

${ }^{4}$ AYOUB, E. Ginástica geral e educação física escolar. 2. ed. Campinas: Ed. da UNICAMP, 2004.

${ }^{5}$ NUnOMURA, M.; TSUKAMOTO, M. H. C. (Org.). Fundamentos das ginásticas. Jundiaí: Fontoura, 2009.

${ }^{6}$ KUNZ, E. Transformação didático-pedagógica do esporte. Ijuí: Ed. da Unijuí, 1994.

${ }^{7}$ SASSAKI, R. K. Inclusão, construindo uma sociedade para todos. 7. ed. Rio de Janeiro: WVA, 2006.

${ }^{8}$ IBIAPINA, I. M. L. M. Pesquisa colaborativa: investigação, formação e produção de conhecimentos. Brasília: Líber Livro, 2008.

${ }^{9}$ BARDIN, L. Análise de conteúdo. Lisboa: Edições 70, 2004.

${ }^{10}$ KUNZ, E. (Org.). Didática da Educação Física 1. 3. ed. Iuí: Ed. da Unijuí, 2003.

${ }^{11}$ BIANCHETTI, L.; CORREIA, J. A. In/exclusão no trabalho e na educação: aspectos mitológicos, históricos e conceituais - Campinas: Papirus, 2011. 
${ }^{12}$ OLIVEIRA, M. K. Vygotsky, aprendizado e desenvolvimento: um processo sóciohistórico. São Paulo, SP: Editora Scipione, 1993.

${ }^{13}$ KUNZ, E. Educação Física: ensino e mudanças. Ijuí: Ed. da Unijuí, 1991.

${ }^{14}$ SILVA, S. M. C.; ALMEIDA, C. M. C.; FERREIRA, S. Apropriação cultural e mediação pedagógica: contribuições de Vigotski na discussão do tema. Psicologia em Estudo, Maringá, v. 16, n. 2, p. 219-228, abr./jun. 2011. Disponível em: $<$ http://www.scielo.br/scielo.php?pid=S1413-73722011000200005\&script=sci_arttext $>$. Acesso em: 03 ago. 2012.

${ }^{15}$ VYGOTSKY, L. S. A formação social da mente. São Paulo: Martins Fontes, 1991.

${ }^{16}$ NÓVOA, A. Formação de professor e profissão docente. In: (Org.). Os professores e a sua formação. Lisboa: Dom Quixote, 1992.

${ }^{1}$ BELLONI, M. L. Infância, mídias e educação: revisitando o conceito de socialização. Perspectiva, Florianópolis, v. 25, n. 1, 41-56, jan./jun. 2007. 